\title{
A New Flexibility Based Damage Index for Damage Detection of Truss Structures
}

\author{
M. Montazer and S. M. Seyedpoor \\ Department of Civil Engineering, Shomal University, Amol 46161-84596, Iran \\ Correspondence should be addressed to S. M. Seyedpoor; s.m.seyedpoor@gmail.com
}

Received 19 July 2013; Accepted 15 November 2013; Published 16 March 2014

Academic Editor: Gyuhae Park

Copyright ( 2014 M. Montazer and S. M. Seyedpoor. This is an open access article distributed under the Creative Commons Attribution License, which permits unrestricted use, distribution, and reproduction in any medium, provided the original work is properly cited.

\begin{abstract}
A new damage index, called strain change based on flexibility index (SCBFI), is introduced to locate damaged elements of truss systems. The principle of SCBFI is based on considering strain changes in structural elements, between undamaged and damaged states. The strain of an element is evaluated using the columnar coefficients of the flexibility matrix estimated via modal analysis information. Two illustrative test examples are considered to assess the performance of the proposed method. Numerical results indicate that the method can provide a reliable tool to accurately identify the multiple-structural damage for truss structures.
\end{abstract}

\section{Introduction}

Structural damage detection has a great importance in civil engineering. Neglecting the local damage may cause the reduction of the functional age of a structural system or even an overall failure of the structure. Therefore, damage detection is an important issue in structural engineering. The basis of many damage identification procedures is observing the changes in structural responses. Damage reduces structure's stiffness and mass, which leads to a change in the static and dynamic responses of the structure. Therefore, the damage detection techniques are generally classified into two main categories. They include the dynamic and static identification methods requiring the dynamic and static test data, respectively. Because of the global nature of the dynamic responses of a structure, techniques for detecting damage based on vibration characteristics of structures have been gaining importance.

Presence of a crack or localized damage in a structure reduces its stiffness leading to the decrease of the natural frequencies and the change of vibration modes of the structure [1-3]. Many researchers have used one or more of these characteristics to detect and locate the structural damage. Cawley and Adams [4] used the changes in the natural frequencies together with a finite element model to locate the damage site. Although it is fairly easy to detect the presence of damage in a structure from changes in the natural frequencies, it is difficult to determine the location of damage. This is because damage at two different locations associated with a certain amount of damage may produce the same amount of frequency change. Furthermore, in the case of symmetric structures, the changes in the natural frequencies due to damage at two symmetric locations are exactly the same. There is thus a need for a more comprehensive method of damage assessment in structures. To overcome this drawback, mode shapes have been used for identifying the damage location $[5,6]$. Displacement mode shapes can be obtained by experimental tools but an accurate characterization of the damage location from these parameters requires measurements in many locations. Therefore, using the changes in mode shapes between damaged and undamaged structures may not be very efficient. Mannan and Richardson utilized the frequency response function (FRF) measurements for detecting and locating the structural cracks [7]. Pandey and Biswas used the change in flexibility matrix to detect damage in a beam [8]. Raghavendrachar and Aktan calculated the flexibility matrix based on mode shapes and demonstrated the advantages of using the flexibility compared to the mode shapes [9]. The influence of statistical errors on damage detection based on structural flexibility and mode shape curvature has been investigated by Tomaszewska [10]. The generalized flexibility matrix change to detect the location and extent of structural 
damage has been introduced by Li et al. [11]. Compared with the original flexibility matrix based approach, the effect of truncating higher-order modes can be considerably reduced in the new approach. A method based on best achievable flexibility change with capability in detecting the location and extent of structural damage has also been presented by Yang and Sun [12]. A method for structural damage identification based on flexibility disassembly has also been proposed by Yang [13]. The efficiency of the proposed method has been demonstrated by numerical examples. A flexibility based damage index has been proposed for structural damage detection by Zhang et al. [14]. Example of a 12-storey building model illustrated the efficiency of the proposed index for successfully detecting damage locations in both the single and multiple damage cases. The flexibility matrix and strain energy concepts of a structure have been used by Nobahari and Seyedpoor [15] in order to introduce a damage indicator for locating structural damage.

In this paper, a new index for structural damage detection is proposed. The principle of the index is based on comparison of structural element's strains obtained from two sets related to intact and damaged structure. The calculation of the strain is based on a flexibility matrix estimated from modal analysis information. Taking advantage of highly converged flexibility matrix using only few vibration modes related to low frequencies in the first phase and then determining the elemental strain using the flexibility coefficients develop a robust tool for damage localization of truss structures.

\section{Structural Damage Detection}

In recent years, many damage indices have been proposed to identify structural damage. In this paper, a number of widely used indices are first described and then the new proposed damage index is introduced.

\subsection{Modal Assurance Criterion (MAC) and Coordinate Modal} Assurance Criterion (COMAC). Based on the basic modal parameters of structures such as natural frequencies, damping ratios, and mode shapes, some coefficients derived from these parameters can be useful for damage detection. The MAC and COMAC factors [16] may be mentioned in this category. The factors are derived from mode shapes and express the correlation between two mode shapes obtained from two sets. Sufficient number of degrees of freedom (number of measurement points) are needed here to attain good accuracy.

Let $\left[\varphi_{A}\right]$ and $\left[\varphi_{B}\right]$ be the first and second sets of measured mode shapes in a matrix form of size $n \times m_{A}$ and $n \times m_{B}$, respectively. $m_{A}$ and $m_{B}$ are the numbers of mode shapes considered in the respective sets and $n$ is the number of measurement points. The MAC factor is then defined for the mode shapes $j$ and $k$ as follows:

$$
\operatorname{MAC}_{(j k)}=\frac{\left|\sum_{i=1}^{n}\left[\varphi_{A}\right]_{i}^{j} \cdot\left[\varphi_{B}\right]_{i}^{k}\right|^{2}}{\sum_{i=1}^{n}\left(\left[\varphi_{A}\right]_{i}^{j}\right)^{2} \cdot \sum_{i=1}^{n}\left(\left[\varphi_{B}\right]_{i}^{k}\right)^{2}}
$$

where $j=1, \ldots, m_{A}$ and $k=1, \ldots, m_{B} ;\left[\varphi_{A}\right]_{i}^{j}$ and $\left[\varphi_{B}\right]_{i}^{k}$ are the $i$ th components of the modes $\left[\varphi_{A}\right]^{j}$ and $\left[\varphi_{B}\right]^{k}$, respectively. The $\mathrm{MAC}_{(j k)}$ factor indicates the degree of correlation between the $j$ th mode of the first set $A$ and the $k$ th mode of the second set $B$. The MAC values vary from 0 to 1 , with 0 for no correlation and 1 for full correlation. Therefore, if the eigenvectors $\left[\varphi_{A}\right]$ and $\left[\varphi_{B}\right]$ are identical, the corresponding MAC values will be close to 1 , thus indicating the full correlation between the two modes. The deviation of the factors from 1 can be interpreted as a damage indicator in a structure.

The COMAC factors are generally used to identify where the mode shapes of the structure from two sets of measurements do not correlate. If the modal displacements in a coordinate $j$ from two sets of measurements are identical, the COMAC factor is close to 1 for this coordinate. A large deviation from unity can be interpreted as damage indication in the structure. For the coordinate $p$ of a structure using $m$ mode shapes, the COMAC factor is defined as follows:

$$
\operatorname{COMAC}_{p}=\frac{\left|\sum_{i=1}^{m}\left[\varphi_{A}\right]_{i}^{p} \cdot\left[\varphi_{B}\right]_{i}^{p}\right|^{2}}{\sum_{i=1}^{m}\left(\left[\varphi_{A}\right]_{i}^{p}\right)^{2} \cdot \sum_{i=1}^{m}\left(\left[\varphi_{B}\right]_{i}^{p}\right)^{2}}
$$

In practice, only a few mode shapes of a structure can be measured. As a result, a method capable of predicting structural damage that requires a limited number of mode shapes would be more efficient.

2.2. Flexibility Method. It has been proved that the presence of damage in a structure increases its flexibility. So, any change observed in the flexibility matrix can be interpreted as a damage indication in the structure and allows one to identify damage [17]. Therefore, another class of damage identification methods is based on using the flexibility matrix. The flexibility matrix $F$ is the inverse of the stiffness matrix $K$ relating the applied static forces $\{f\}$ to resulting structural displacements $\{u\}$ as

$$
\{u\}=[F]\{f\} .
$$

The flexibility matrix can be also dynamically measured from modal analysis data. The relationship between the flexibility matrix $F$ and the dynamic characteristics of a structure can be given by $[15,17]$ :

$$
F=[\varphi][\Lambda]^{-1}[\varphi]^{T} \simeq \sum_{i=1}^{n m} \frac{1}{\omega_{i}^{2}} \varphi_{i} \varphi_{i}^{T},
$$

where $[\varphi]$ is the mode shape matrix; $[\Lambda]=\operatorname{diag}\left(1 / \omega^{2}\right)$ is a diagonal matrix; $\omega_{i}$ is the $i$ th circular frequency; $\varphi_{i}$ is the mass-normalized $i$ th mode shape of the structure; and $n m$ is the number of measured modes.

From (4), one can see that the modal contribution to the flexibility matrix decreases as the frequency increases. On the other hand, the flexibility matrix converges rapidly with the increase of the values of the frequencies. Therefore, from only a few of lower modes, a good estimate for the flexibility matrix can be achieved. 
The principle of flexibility method is based on a comparison of the flexibility matrices from two sets of mode shapes. If $F_{h}$ and $F_{d}$ are the flexibility matrices corresponding to the healthy and damaged states of the structure, a flexibility change matrix $\Delta F$ can be defined as the difference of the two matrices:

$$
\Delta F=F_{d}-F_{h}
$$

For each degree of freedom, let $\bar{\delta}_{j}$ be the maximum absolute value of the elements in the corresponding column of $\Delta F$ :

$$
\bar{\delta}_{j}=\max \left|\delta_{i j}\right|
$$

where $\delta_{i j}$ are the elements of $\Delta F$. In order to identify damage in the structure, the quantity $\bar{\delta}_{j}$ can be used as a damage indicator [17].

2.3. Modal Strain Energy Based Method. The methods based on modal strain energy of a structure have been commonly used in damage detection [17-19]. Since the mode shape vectors are equivalent to nodal displacements of a vibrating structure, therefore in each element of the structure strain energy is stored. The strain energy of a structure due to mode shape vectors is usually referred to as modal strain energy (MSE) and can be considered as a valuable parameter for damage identification. The modal strain energy of eth element in $i$ th mode of the structure can be expressed as [19]:

$$
\mathrm{mse}_{i}^{e}=\frac{1}{2} \varphi_{i}^{e^{T}} K^{e} \varphi_{i}^{e} \quad i=1,2, \ldots n m, e=1,2, \ldots n t e
$$

where $K^{e}$ is the stiffness matrix of $e$ th element of the structure and $\varphi_{i}^{e}$ is the vector of corresponding nodal displacements of element $e$ in mode $i$.

A normalized form of MSE considering $\mathrm{nm}$ vibrating modes of the structure proposed in [19] can be given as

$$
\mathrm{mnmse}^{e}=\frac{\sum_{i=1}^{n m}\left(\mathrm{mse}_{i}^{e} / \sum_{e=1}^{n t e} \mathrm{mse}_{i}^{e}\right)}{n m}, \quad e=1, \ldots n t e .
$$

The damage occurrence increases the MSE and consequently the efficient parameter mnmse $e^{e}$. So, by determining the parameter mnmse $e^{e}$ for each element of healthy and damaged structures, an efficient indicator for identifying the damage in the element can be defined [19].

\section{The Proposed Strain Change Based on Flexibility Index (SCBFI)}

In this study, a new damage detection index based on considering strain changes in a structural element, due to damage, is developed. The new index SCBFI proposed is capable of identifying and locating the multiple-structural damage in truss structures. The principle of the new index is based on evaluating the changes of strain in structural elements, but the method of computing the strain is completely different from the usual methods. The nodal displacement vector used for computing the strain obtains from the flexibility matrix of the structure. Moreover, the flexibility matrix is determined from modal analysis information including mode shapes and natural frequencies. Taking advantage of rapid convergence of the flexibility matrix in terms of the number of vibration modes helps the proposed index to identify the structural damage with more efficiency and lower computational cost.

As the first step for constructing the proposed damage index, a modal analysis is required to be performed. The modal analysis is a tool to determine the natural frequencies and mode shapes of a structure [20]. It has the mathematical form of

$$
\left(K-\omega_{i}^{2} M\right) \varphi_{i}=0, \quad i=1,2, \ldots n m,
$$

where $K$ and $M$ are the stiffness and mass matrices of the structure, respectively. Also, $\omega_{i}$ and $\varphi_{i}$ are the $i$ th circular frequency and mode shape vector of the structure, respectively.

At the second step, the flexibility matrix of healthy and damaged structure (FMH, FMD), related to the dynamic characteristics of the healthy and damaged structure, can be approximated as

$$
\begin{aligned}
& \mathrm{FMH} \simeq \sum_{i=1}^{n m} \frac{1}{\left(\omega_{i}^{h}\right)^{2}} \varphi_{i}^{h} \varphi_{i}^{h^{T}}, \\
& \mathrm{FMD} \simeq \sum_{i=1}^{n m} \frac{1}{\left(\omega_{i}^{d}\right)^{2}} \varphi_{i}^{d} \varphi_{i}^{d^{T}},
\end{aligned}
$$

where $\omega_{i}^{h}$ and $\omega_{i}^{d}$ are the ith circular frequency of healthy and damaged structure, respectively; $\varphi_{i}^{h}$ and $\varphi_{i}^{d}$ are the $i$ th mode shape vector of healthy and damaged structure, respectively; and $n m$ is the number of vibrating modes considered.

It can be observed that all components of the mode shapes are required to be measured and it is not a realistic assumption for operational damage detection. However, for actual use of the suggested method, it is not needed to measure the full set of mode shapes. The mode shapes of the damaged structure in partial degrees of freedom are first measured, and then the incomplete mode shapes are expanded to match all degrees of freedom of the structure by a common technique such as a dynamic condensation method [21].

Since each column of the flexibility matrix represents the displacement pattern of the structure, associated with a unit force applied at the corresponding DOF of that column, therefore they can be used as nodal displacements to calculate the strains of structural elements. The strain of each element of a 2-D truss structure can be expressed as [22]:

$$
\epsilon=\frac{1}{L}\left[\begin{array}{lll}
-\cos \theta-\sin \theta & \cos \theta & \sin \theta
\end{array}\right]\left\{\begin{array}{l}
d_{1 x} \\
d_{1 y} \\
d_{2 x} \\
d_{2 y}
\end{array}\right\},
$$

where $\epsilon$ is the strain of truss element, $L$ is the length of element, $\theta$ is the angle between local and global coordinates, and $d^{T}=\left\{d_{1 x}, d_{1 y}, d_{2 x}, d_{2 y}\right\}$ is the nodal displacement vector of the element. 


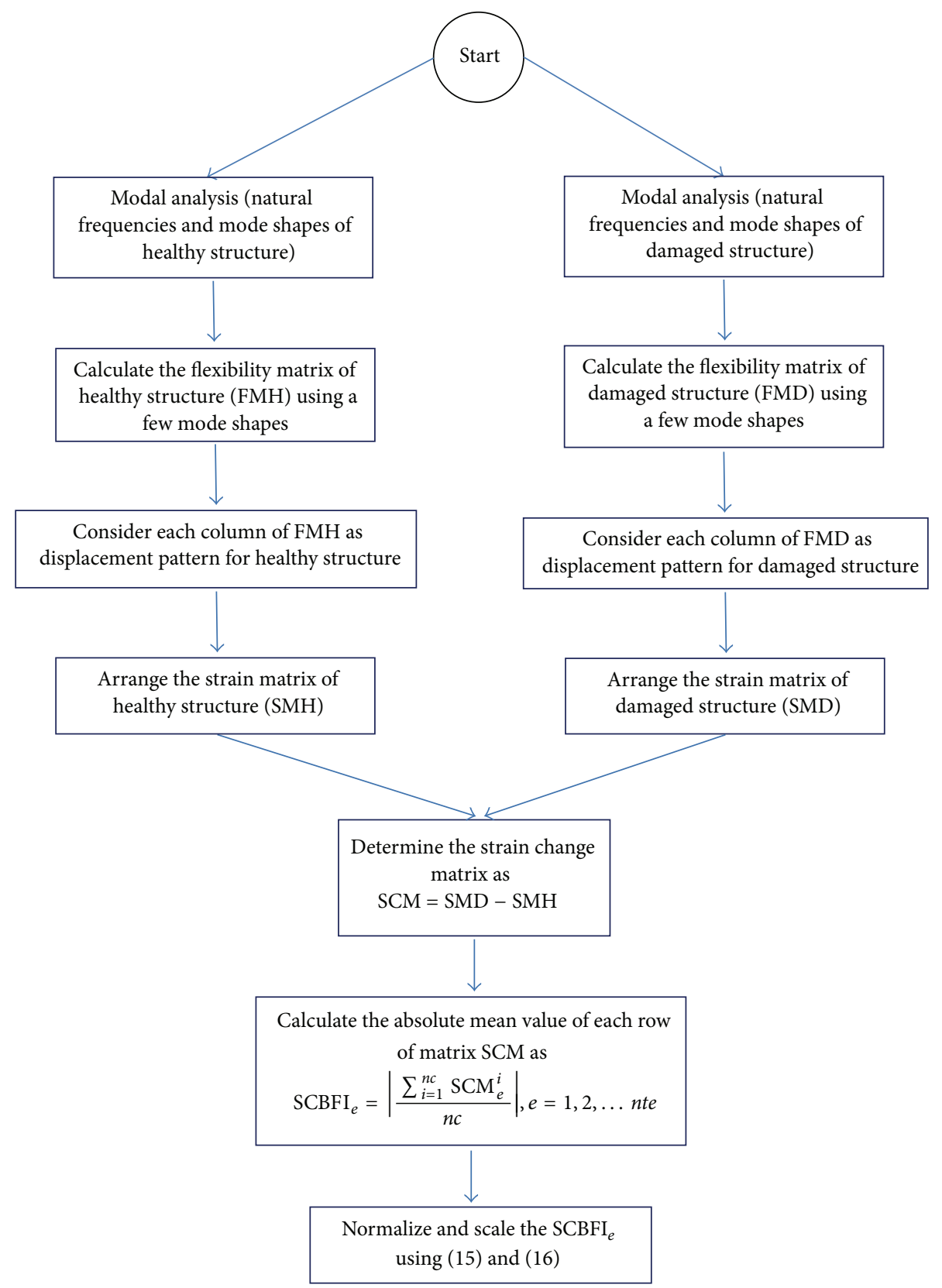

FIGURE 1: The process for constructing the SCBFI index.

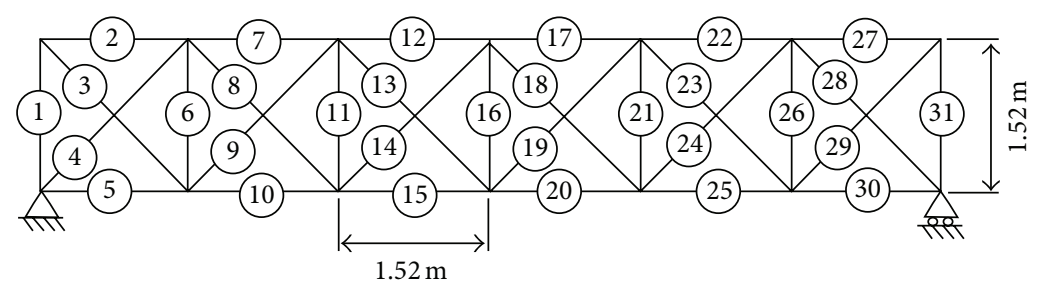

FIGURE 2: Planar truss having 31 elements. 


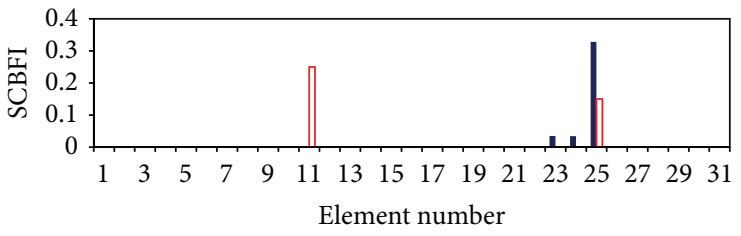

(a)

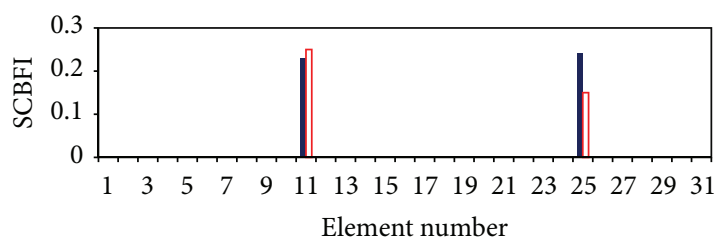

- Identified damage

$\checkmark$ Induced damage

(c)

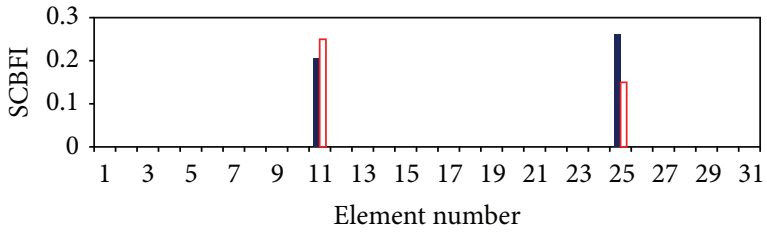

(b)

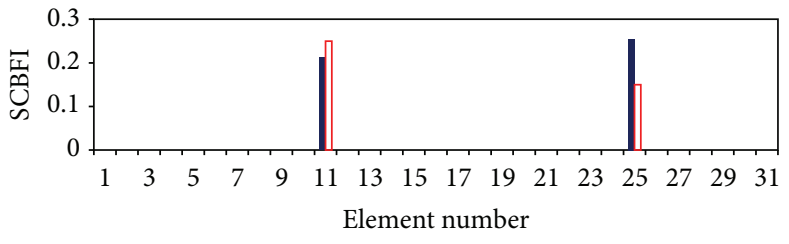

- Identified damage

$\checkmark$ Induced damage

(d)

Figure 3: Damage identification for 31-bar truss for case 1 considering (a) 1 mode, (b) 2 modes, (c) 3 modes, and (d) 4 modes.

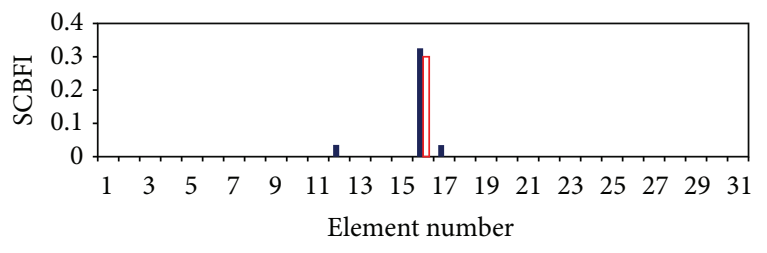

(a)

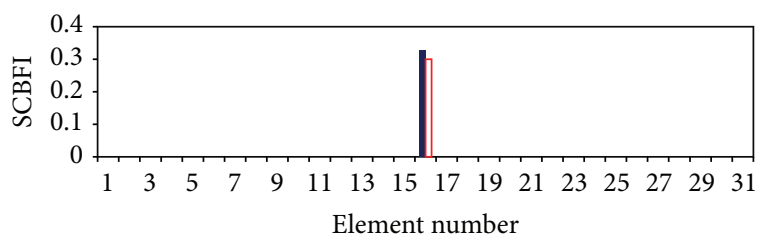

- Identified damage

$\square$ Induced damage

(c)

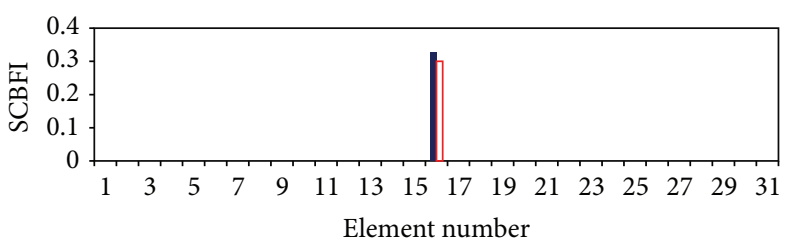

(b)

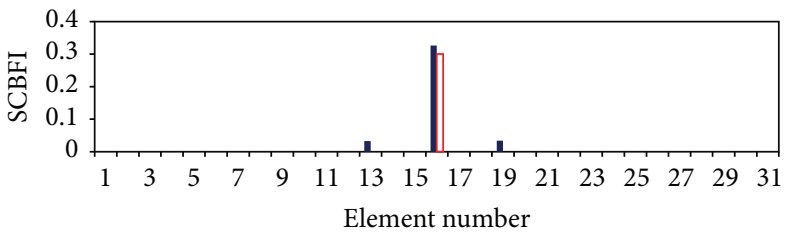

- Identified damage

$\square$ Induced damage

(d)

Figure 4: Damage identification for 31-bar truss for case 2 considering (a) 1 mode, (b) 2 modes, (c) 3 modes, and (d) 4 modes.

So, at the next step, the strain of eth element for $i$ th column of healthy and damaged structure based on the columnar coefficients of the flexibility matrix can be determined as

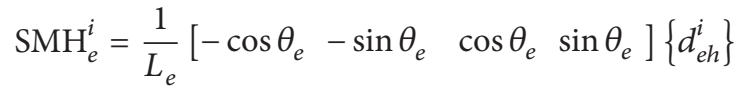

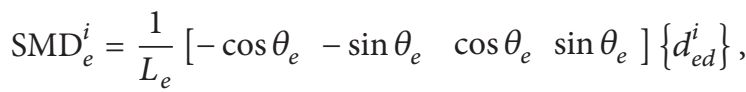

where $\mathrm{SMH}_{e}^{i}$ is the strain of $e$ th element related to $i$ th column of $\mathrm{FMH} ; \mathrm{SMD}_{e}^{i}$ is the strain of eth element related to $i$ th column of FMD; $\left\{d_{e h}^{i}\right\}$ and $\left\{d_{e d}^{i}\right\}$ are the nodal displacement vectors of $e$ th element, associated with the $i$ th column of flexibility matrix for healthy and damaged structure, respectively; $\theta_{e}$ is the angle between local and global coordinates of $e$ th element, and $L_{e}$ is the length of $e$ th element.
Now, the strain change matrix SCM can be defined as the difference between the strain matrix of damaged structure SMD and the strain matrix of healthy structure SMH as

$$
\mathrm{SCM}=\mathrm{SMD}-\mathrm{SMH} \text {. }
$$

The $i$ th row of SCM matrix represents the strain changes of $i$ th element of structure for unit loads applied at different DOFs of the structure. The SCBFI index can now be defined as a columnar vector containing the absolute mean value of each row of SCM matrix given by

$$
\operatorname{SCBFI}_{e}=\left|\frac{\sum_{i=1}^{n c} \mathrm{SCM}_{e}^{i}}{n c}\right|, \quad e=1,2, \ldots n t e,
$$

where $n c$ is the number of columns in the flexibility matrix that is equal to the total degrees of freedom of the structure and nte is the total number of truss elements. 


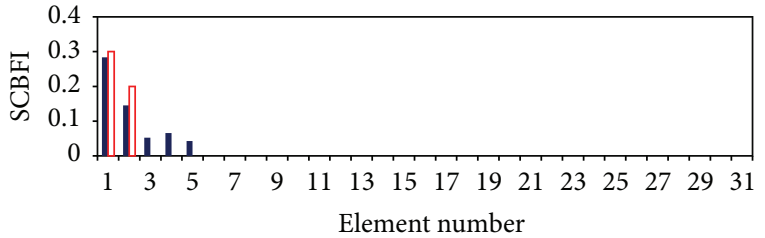

(a)

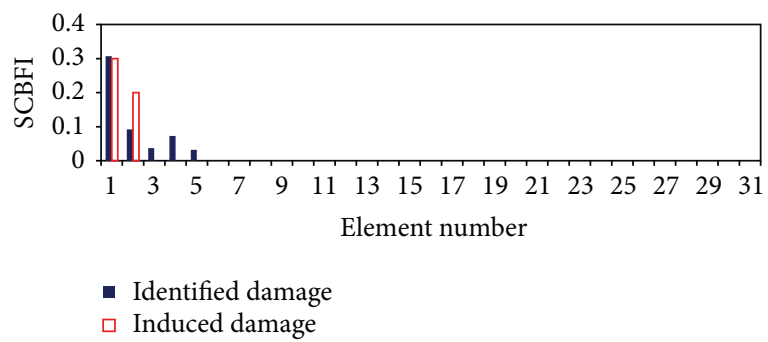

(c)

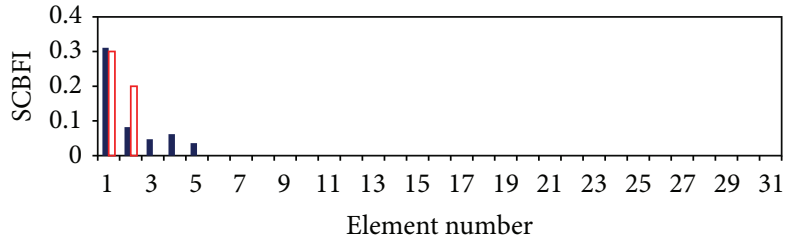

(b)

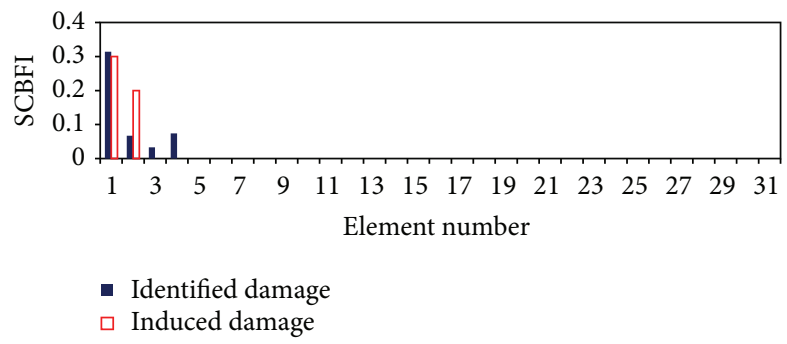

(d)

Figure 5: Damage identification for 31-bar truss for case 3 considering (a) 1 mode, (b) 2 modes, (c) 3 modes, and (d) 4 modes.

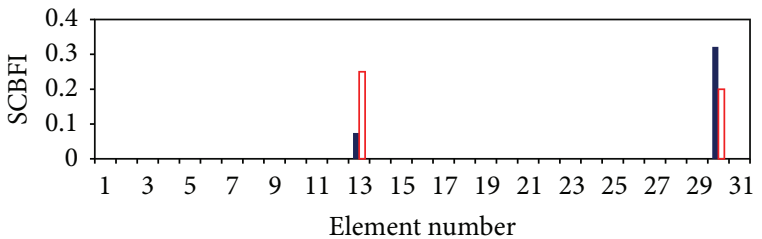

(a)

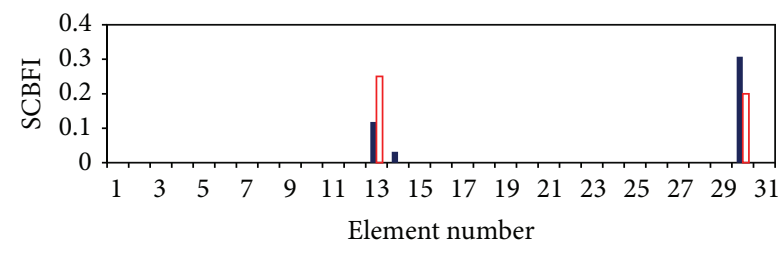

- Identified damage

$\square$ Induced damage

(c)

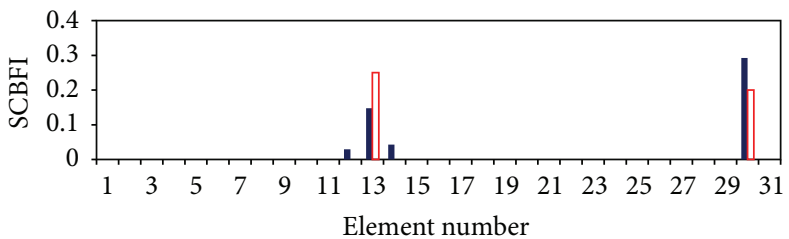

(b)

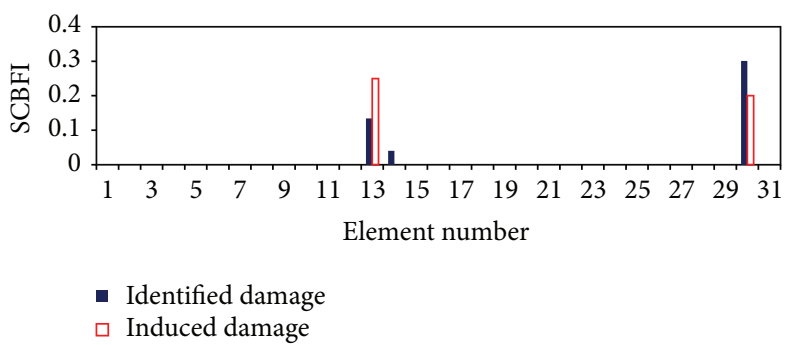

(d)

FIgURE 6: Damage identification for 31-bar truss for case 4 considering (a) 1 mode, (b) 2 modes, (c) 3 modes, and (d) 4 modes.

Theoretically, damage occurrence leads to increasing the SCM and consequently the index $\mathrm{SCBFI}^{e}$. As a result, in this study, by determining the parameter $\mathrm{SCBFI}^{e}$ for each element of the structure, an efficient indicator for estimating the presence and locating the damage in the element can be defined. Assuming that the set of the damage indices $\mathrm{SCBFI}_{e}$ $(e=1,2, \ldots n t e)$ represents a sample population of a normally distributed random variable, a normalized damage index can be defined as follows:

$$
\begin{array}{r}
\mathrm{SCBFI}_{e}^{n}=\left[\frac{\left(\mathrm{SCBFI}_{e}-\operatorname{mean}(\mathrm{SCBFI})\right)}{\operatorname{std}(\mathrm{SCBFI})}\right], \\
e=1,2, \ldots \text { nte, }
\end{array}
$$

where mean(SCBFI) and std(SCBFI) represent the mean and standard deviation of the vector of damage indices, respectively.

In order to obtain a more accurate damage extent for an element, the damage indicator of (15) needs to be further scaled as

$$
\mathrm{SCBFI}_{e}^{n}=\frac{\mathrm{SCBFI}_{e}^{n}}{3\left\|\mathrm{SCBFI}^{n}\right\|}, \quad e=1,2, \ldots n t e,
$$

where $\|\cdot\|$ symbolizes the magnitude of a vector.

The process of constructing the SCBFI index can also be briefly shown in Figure 1. 


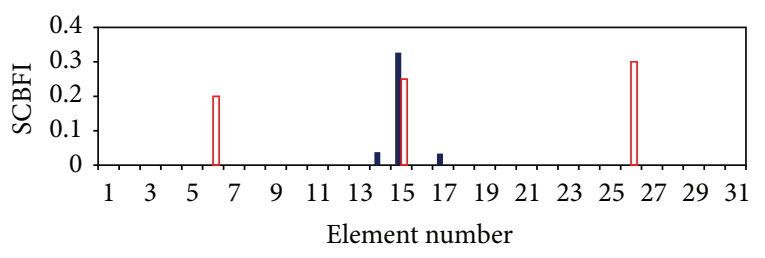

(a)

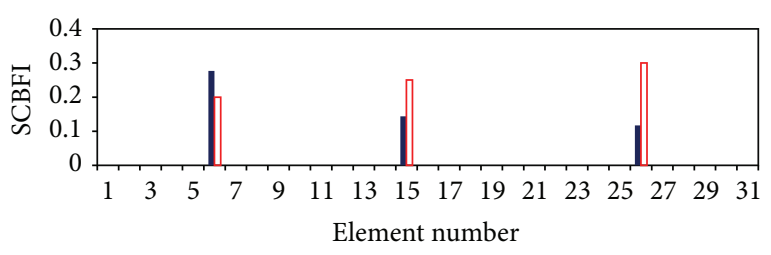

- Identified damage

$\square$ Induced damage

(c)

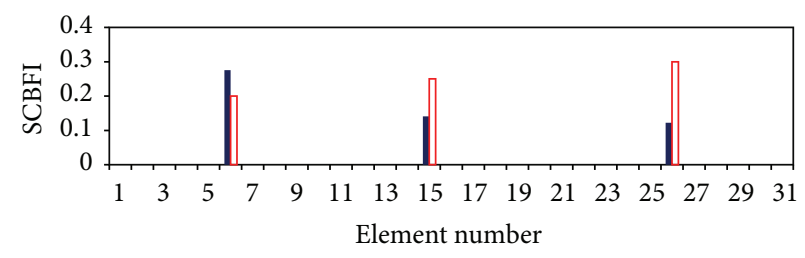

(b)

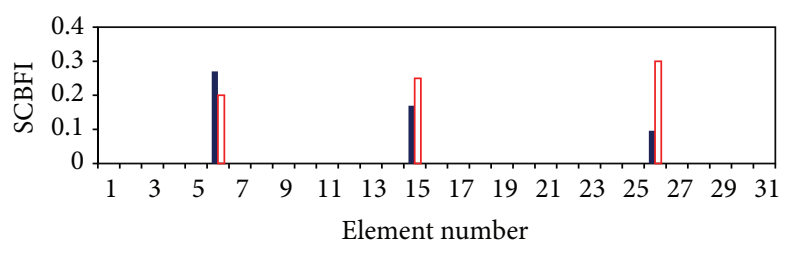

- Identified damage

$\square$ Induced damage

FIGURE 7: Damage identification for 31-bar truss for case 5 considering (a) 1 mode, (b) 2 modes, (c) 3 modes, and (d) 4 modes.

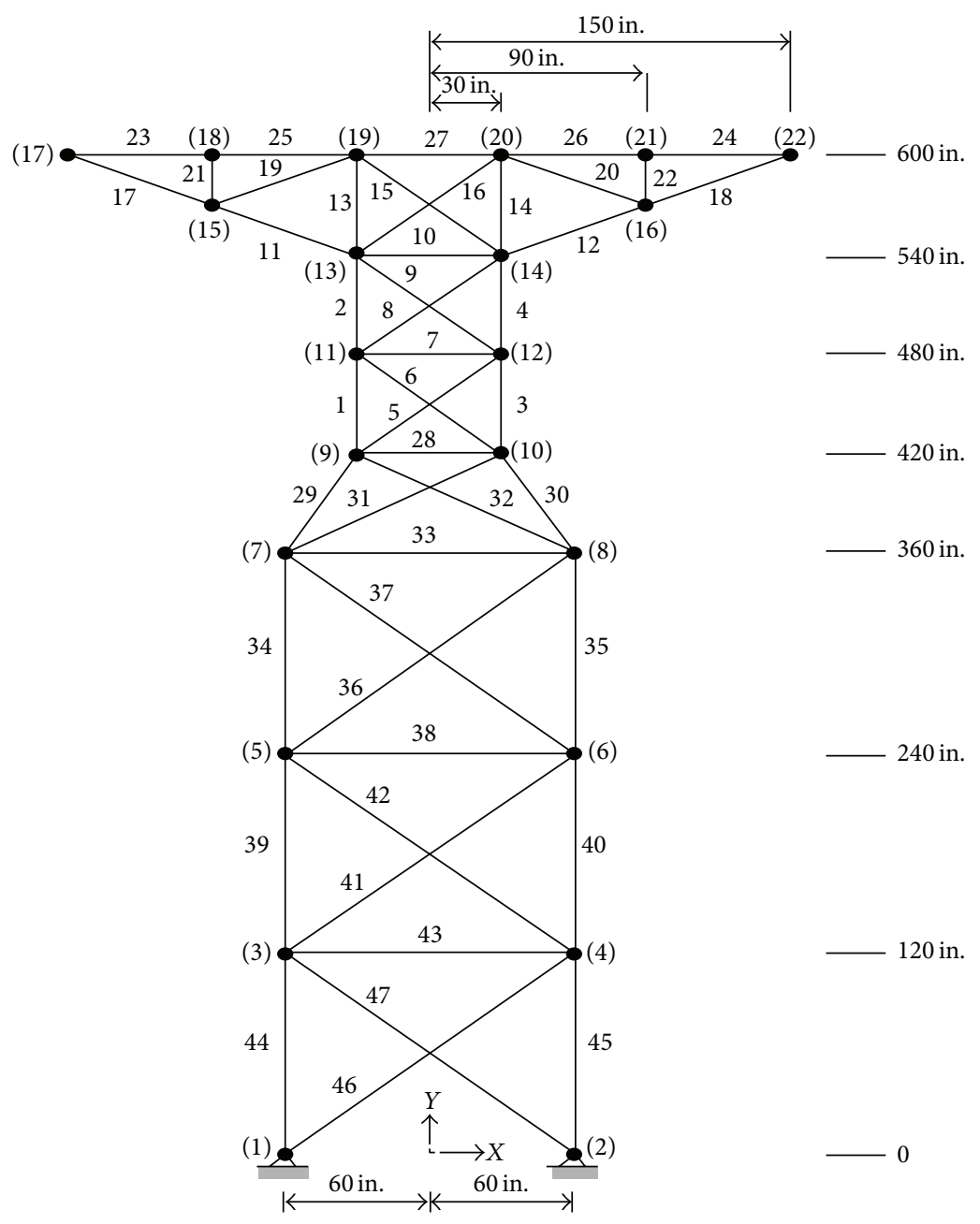

FIGURE 8: Forty-seven-bar planar power line tower. 


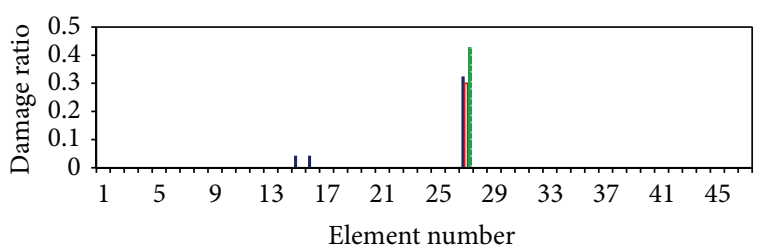

(a)

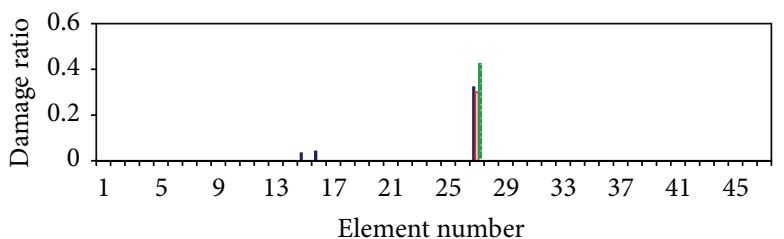

- SCBFI

$\square$ Induced damage

a MSEBI

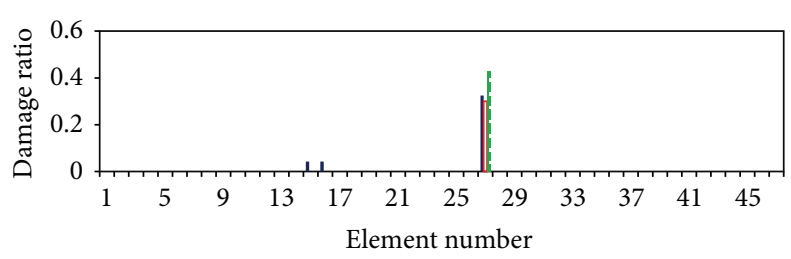

(b)

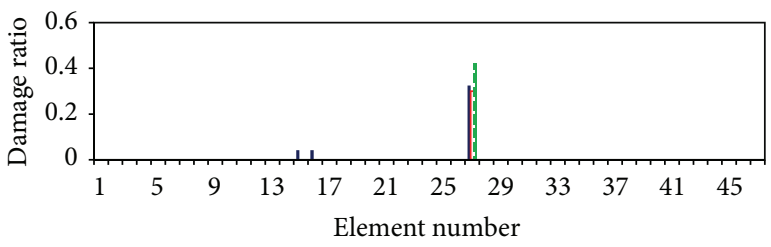

- SCBFI

$\square$ Induced damage

a MSEBI

(c)

(d)

Figure 9: Comparison of damage index SCBFI with MSEBI for 47-bar planar truss for case 1 considering (a) 1 mode, (b) 2 modes, (c) 3 modes, and (d) 4 modes.

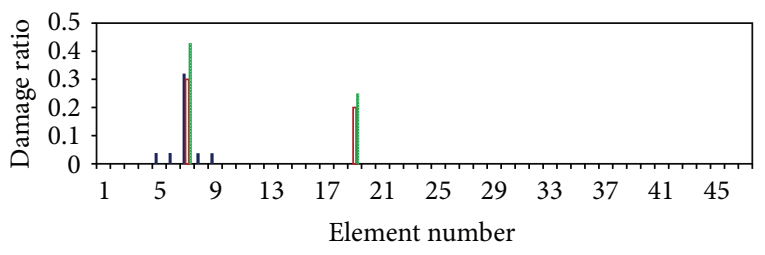

(a)

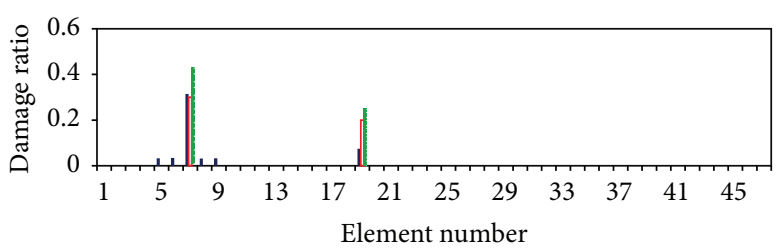

- SCBFI

$\square$ Induced damage

a MSEBI

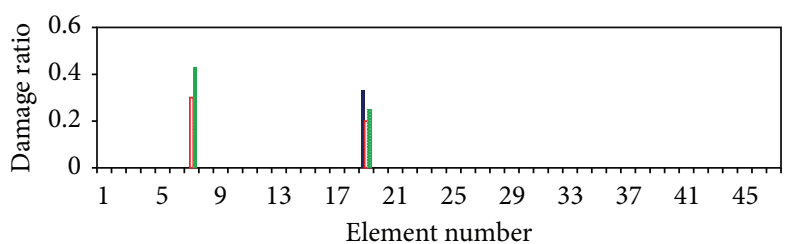

(b)

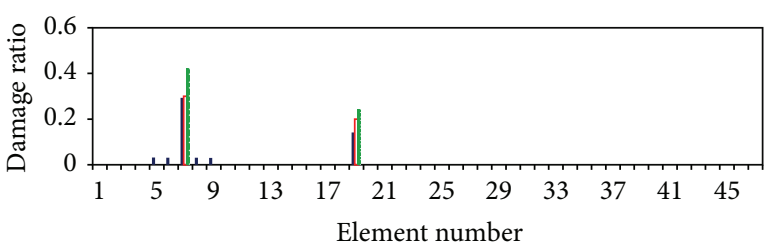

- SCBFI

$\square$ Induced damage

n MSEBI

(c)

(d)

FIgure 10: Comparison of damage index SCBFI with MSEBI for 47-bar planar truss for case 2 considering (a) 1 mode, (b) 2 modes, (c) 3 modes, and (d) 4 modes.

\section{Test Examples}

In order to show the capabilities of the proposed method for identifying the multiple-structural damage, two illustrative test examples are considered. The first example is a 31-bar planar truss and the second one is a 47-bar planar truss. The effect of measurement noise on the performance of the method is considered in the first example.

4.1. Thirty-One-Bar Planar Truss. The 31-bar planar truss shown in Figure 2 selected from [23] is modeled using the conventional finite element method without internal nodes leading to 25 degrees of freedom. The material density and elasticity modulus are $2770 \mathrm{~kg} / \mathrm{m}^{3}$ and $70 \mathrm{GPa}$, respectively. Damage in the structure is simulated as a relative reduction in the elasticity modulus of individual bars. Five different damage cases given in Table 1 are induced in the structure and the proposed method is tested for each case. Figures 3, 4, 5, 6, and 7 show the SCBFI value with respect to element number for damage cases 1 to 5 when one to four mode shapes are considered, respectively.

It can be observed that the new index achieves the actual site of damage truthfully in most cases. It is also revealed that the general configuration of identification charts does not 


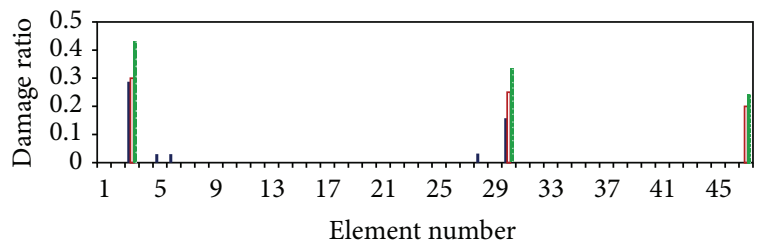

(a)

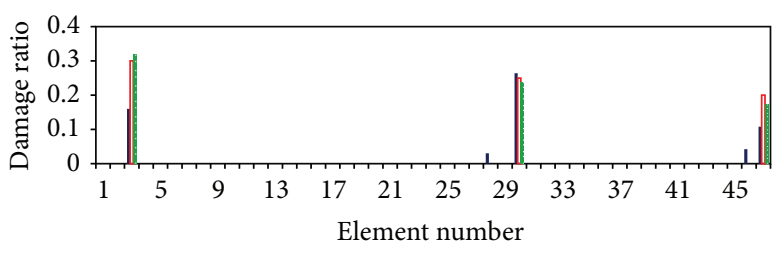

- SCBFI

$\square$ Induced damage

a MSEBI

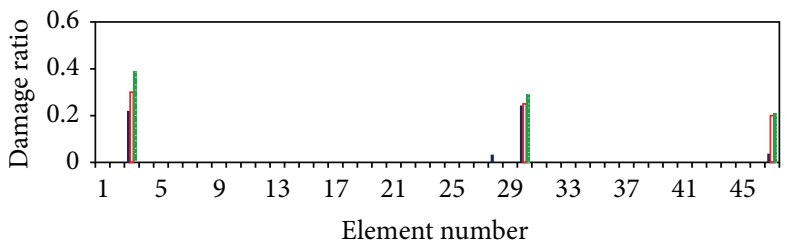

(b)

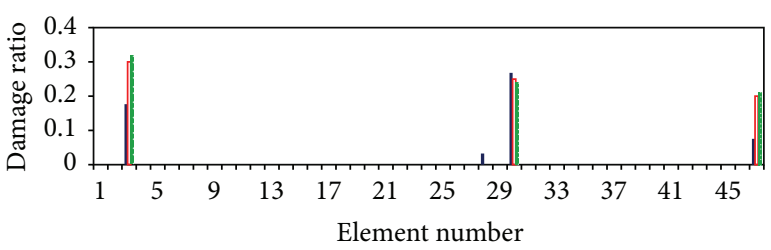

- SCBFI

$\square$ Induced damage

a MSEBI

(c)

(d)

FIGURE 11: Comparison of damage index SCBFI with MSEBI for 47-bar planar truss for case 3 considering (a) 1 mode, (b) 2 modes, (c) 3 modes, and (d) 4 modes.

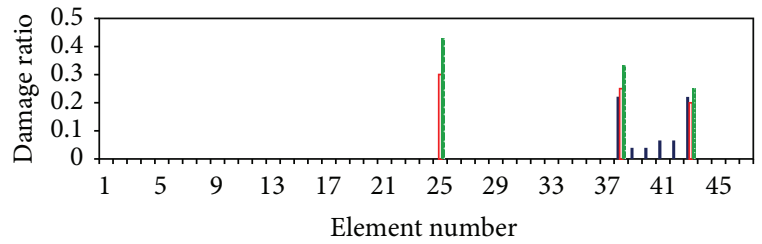

(a)

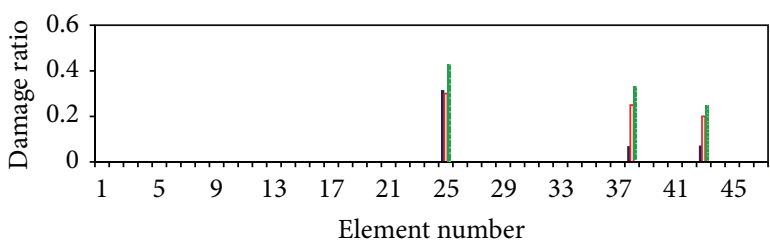

- SCBFI

$\square$ Induced damage

a MSEBI

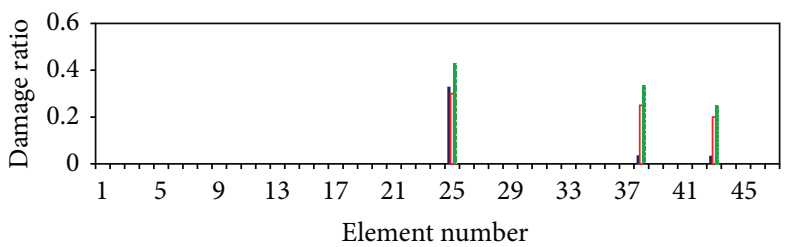

(b)

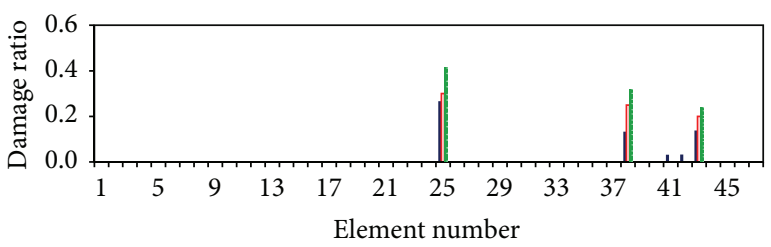

- SCBFI

$\square$ Induced damage

a MSEBI

(c)

(d)

FIGURE 12: Comparison of damage index SCBFI with MSEBI for 47-bar planar truss for case 4 considering (a) 1 mode, (b) 2 modes, (c) 3 modes, and (d) 4 modes.

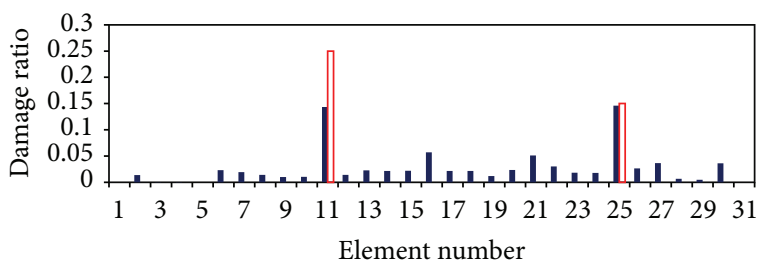

- Noisy SCBFI

$\square$ Induced damage

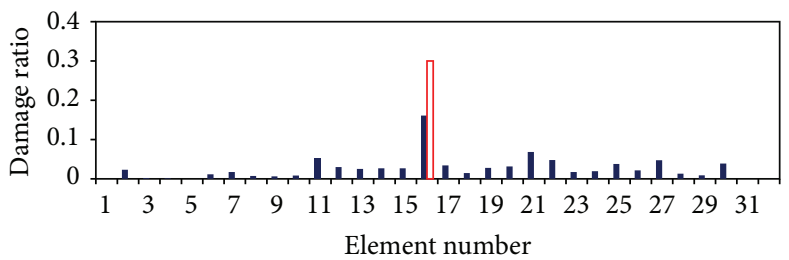

- Noisy SCBFI

$\square$ Induced damage

(a)

(b)

FIGURE 13: The SCBFI for 31-bar truss considering 1\% noise for (a) case 1 and (b) case 2. 


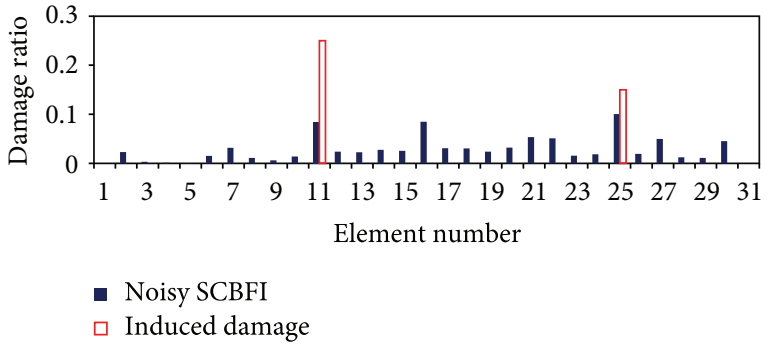

(a)

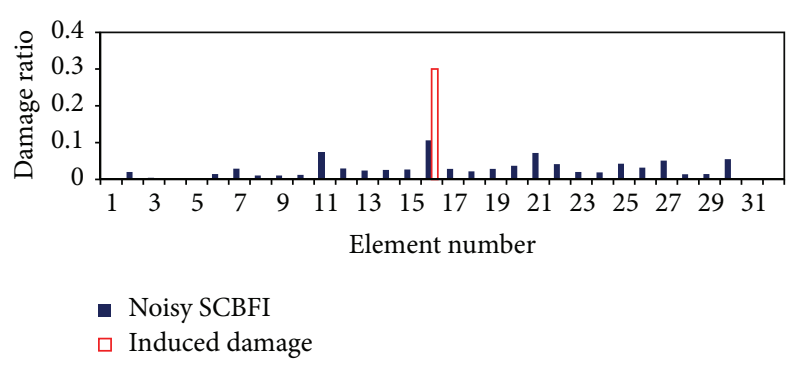

(b)

FIGURE 14: The SCBFI for 31-bar truss considering 2\% noise for (a) case 1 and (b) case 2.

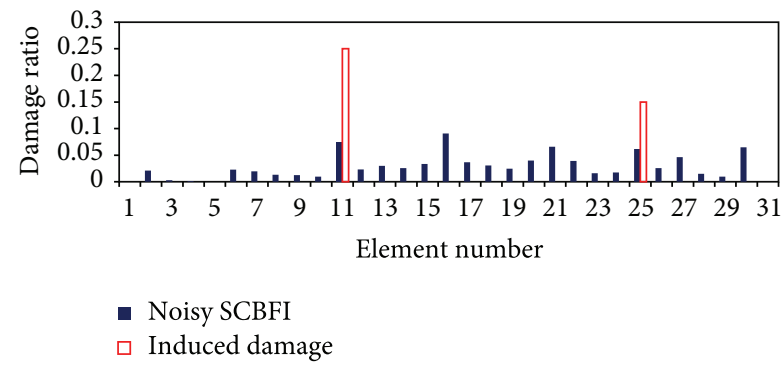

(a)

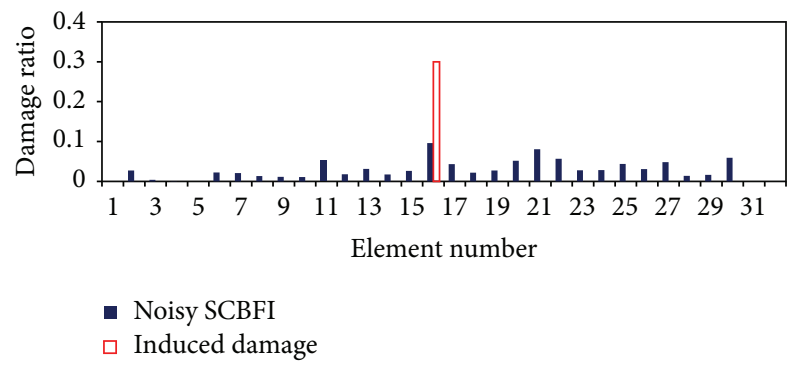

(b)

FIgURE 15: The SCBFI for 31-bar truss considering 3\% noise for (a) case 1 and (b) case 2.

change after considering more than two modes. It means that the elements detected as damaged elements will be constant via increasing the measured mode shapes. Thus, requiring only two mode shapes for damage localization is one of the most important advantages of the proposed index.

4.2. Forty-Seven-Bar Planar Power Line Tower. The 47-bar planar power line tower, shown in Figure 8 , is the second example [24] used to demonstrate the practical capability of the new proposed method. In this problem, the structure has forty-seven members and twenty-two nodes and is symmetric about the $Y$-axis. All members are made of steel, and the material density and modulus of elasticity are $0.3 \mathrm{lb} / \mathrm{in}^{3}$ and $30,000 \mathrm{ksi}$, respectively. Damage in the structure is also simulated as a relative reduction in the elasticity modulus of individual bars. Four different damage cases given in Table 2 are induced in the structure and the performance of the new index (SCBFI) is compared with that of an existing index (MSEBI) [19]. Figures 9, 10, 11, and 12 show the SCBFI and MSEBI values with respect to element number for damage cases 1 to 4 when considering 1 to 4 modes, respectively.

It is observed that the new proposed index can find the actual site of damage truthfully. Moreover, the general configuration of identification charts dose not change when more than 3 structural modes are considered. It means that the elements identified as the damaged elements will be constant via increasing the mode shapes. Thus, requiring only three vibration modes for damage localization is one of the most important advantages of the proposed index that is due to high convergence of the flexibility matrix. Moreover, the comparison of the SCBFI with MSEBI index in Figures 9 to
12 demonstrates the same efficiency of the proposed index for damage localization with respect to MSEBI.

4.3. Analysis of Noise Effect. In order to investigate the noise effect on the performance of the proposed method, the measurement noise is considered here by an error applied to the mode shapes [24]. Figures 13, 14, and 15 show the mean value of SCBFI after 100 independent runs for damage cases 1 and 2 of 31-bar truss using 3 mode shapes when they randomly polluted through $1 \%, 2 \%$, and $3 \%$ noise, respectively.

It can be seen from the Figures 13 and 14, the index can localize the damage accurately when $1 \%$ and $2 \%$ noise, respectively are considered; however, the identification results of the method for 3\% noise are not appropriate.

\section{Conclusion}

An efficient damage indicator called here as strain change based on flexibility index (SCBFI) has been proposed for locating multiple damage cases of truss systems. The SCBFI is based on the change of elemental strain computed from the flexibility matrix of a structure between the undamaged structure and damaged structure. Since the flexibility matrix used in the calculation of elemental strains converges rapidly with lower frequencies and mode shapes, it will be useful in decreasing the computational cost. In order to assess the performance of the proposed method for structural damage detection, two illustrative test examples selected from the 
TABLE 1: Five different damage cases induced in 31-bar planar truss.

\begin{tabular}{lccccccccc}
\hline \multicolumn{2}{c}{ Case 1 } & \multicolumn{2}{c}{ Case 2 } & \multicolumn{2}{c}{ Case 3 } & \multicolumn{2}{c}{ Case 4 } & \multicolumn{2}{c}{ Case 5 } \\
$\begin{array}{l}\text { Element } \\
\text { number }\end{array}$ & $\begin{array}{c}\text { Damage } \\
\text { ratio }\end{array}$ & $\begin{array}{c}\text { Element } \\
\text { number }\end{array}$ & $\begin{array}{c}\text { Damage } \\
\text { ratio }\end{array}$ & $\begin{array}{c}\text { Element } \\
\text { number }\end{array}$ & $\begin{array}{c}\text { Damage } \\
\text { ratio }\end{array}$ & $\begin{array}{c}\text { Element } \\
\text { number }\end{array}$ & $\begin{array}{c}\text { Damage } \\
\text { ratio }\end{array}$ & $\begin{array}{c}\text { Element } \\
\text { number }\end{array}$ & $\begin{array}{c}\text { Damage } \\
\text { ratio }\end{array}$ \\
\hline 11 & 0.25 & 16 & 0.30 & 1 & 0.30 & 13 & 0.25 & 6 \\
25 & 0.15 & - & - & 2 & 0.20 & 30 & 0.2 & 15 & 0.20 \\
- & - & - & - & - & - & - & - & 26 & 0.30 \\
\hline
\end{tabular}

TABLE 2: Four different damage cases induced in 47-bar planar power line tower.

\begin{tabular}{|c|c|c|c|c|c|c|c|}
\hline \multicolumn{2}{|c|}{ Case 1} & \multicolumn{2}{|c|}{ Case 2} & \multicolumn{2}{|c|}{ Case 3} & \multicolumn{2}{|c|}{ Case 4} \\
\hline Element number & Damage ratio & Element number & Damage ratio & Element number & Damage ratio & Element number & Damage ratio \\
\hline 27 & 0.30 & 7 & 0.30 & 3 & 0.30 & 25 & 0.30 \\
\hline - & - & 19 & 0.20 & 30 & 0.25 & 38 & 0.25 \\
\hline - & - & - & - & 47 & 0.20 & 43 & 0.20 \\
\hline
\end{tabular}

literature have been considered. The numerical results considering the measurement noise demonstrate that the method can provide an efficient tool for properly locating the multiple damage in the truss systems while needing just three vibration modes. In addition, according to the numerical results, the independence of SCBFI with respect to the mode numbers is the main advantage of the method for damage identification without needing the higher frequencies and mode shapes which are practically difficult and experimentally limited to measure.

\section{Conflict of Interests}

The authors declare that there is no conflict of interests regarding the publication of this paper.

\section{References}

[1] R. D. Adams, P. Cawley, C. J. Pye, and B. J. Stone, "A vibration technique for non-destructively assessing the integrity of structures," Journal of Mechanical Engineering Science, vol. 20, no. 2, pp. 93-100, 1978.

[2] P. Gudmundson, "The dynamic behaviour of slender structures with cross-sectional cracks," Journal of the Mechanics and Physics of Solids, vol. 31, no. 4, pp. 329-345, 1983.

[3] T. K. Obrien, "Stiffness change as a non-destructive damage measurement," in Mechanics of Non-Destructive TestIng, W. W. Stinchcomb, Ed., pp. 101-121, Plenum Press, New York, NY, USA, 1980.

[4] P. Cawley and R. D. Adams, "The location of defects in structures from measurements of natural frequencies," The Journal of Strain Analysis for Engineering Design, vol. 14, no. 2, pp. 49-57, 1979.

[5] A. K. Pandey, M. Biswas, and M. M. Samman, "Damage detection from changes in curvature mode shapes," Journal of Sound and Vibration, vol. 145, no. 2, pp. 321-332, 1991.

[6] J.-T. Kim, Y.-S. Ryu, H.-M. Cho, and N. Stubbs, "Damage identification in beam-type structures: frequency-based method vs mode-shape-based method," Engineering Structures, vol. 25, no. 1, pp. 57-67, 2003.
[7] M. A. Mannan and M. H. Richardson, "Detection and location of structural cracks using FRF measurements," in Proceedings of the 8th International Modal Analysis Conference (IMAC '90), pp. 652-657, 1990.

[8] A. K. Pandey and M. Biswas, "Damage detection in structures using changes in flexibility," Journal of Sound and Vibration, vol. 169, no. 1, pp. 3-17, 1994.

[9] M. Raghavendrachar and A. Aktan, "Flexibility by multireference impact testing for bridge diagnostics," Journal of Structural Engineering, vol. 118, no. 8, pp. 2186-2203, 1992.

[10] A. Tomaszewska, "Influence of statistical errors on damage detection based on structural flexibility and mode shape curvature," Computers and Structures, vol. 88, no. 3-4, pp. 154-164, 2010.

[11] J. Li, B. Wu, Q. C. Zeng, and C. W. Lim, "A generalized flexibility matrix based approach for structural damage detection," Journal of Sound and Vibration, vol. 329, no. 22, pp. 4583-4587, 2010.

[12] Q. W. Yang and B. X. Sun, "Structural damage identification based on best achievable flexibility change," Applied Mathematical Modelling, vol. 35, no. 10, pp. 5217-5224, 2011.

[13] Q. W. Yang, "A new damage identification method based on structural flexibility disassembly," JVC/Journal of Vibration and Control, vol. 17, no. 7, pp. 1000-1008, 2011.

[14] J. Zhang, P. J. Li, and Z. S. Wu, "A new flexibility-based damage index for structural damage detection," Smart Materials and Structures, vol. 22, pp. 25-37, 2013.

[15] M. Nobahari and S. M. Seyedpoor, "An efficient method for structural damage localization based on the concepts of flexibility matrix and strain energy of a structure," Structural Engineering and Mechanics, vol. 46, no. 2, pp. 231-244, 2013.

[16] J.-M. Ndambi, J. Vantomme, and K. Harri, "Damage assessment in reinforced concrete beams using eigenfrequencies and mode shape derivatives," Engineering Structures, vol. 24, no. 4, pp. 501$515,2002$.

[17] A. Alvandi and C. Cremona, "Assessment of vibration-based damage identification techniques," Journal of Sound and Vibration, vol. 292, no. 1-2, pp. 179-202, 2006.

[18] H. W. Shih, D. P. Thambiratnam, and T. H. T. Chan, "Vibration based structural damage detection in flexural members using multi-criteria approach," Journal of Sound and Vibration, vol. 323, no. 3-5, pp. 645-661, 2009. 
[19] S. M. Seyedpoor, "A two stage method for structural damage detection using a modal strain energy based index and particle swarm optimization," International Journal of Non-Linear Mechanics, vol. 47, no. 1, pp. 1-8, 2012.

[20] M. Paz and W. Leigh, Structural Dynamics: Theory and Computation, Springer, 5th edition, 2006.

[21] R. D. Cook, D. S. Malkus, and M. E. Plesha, Concepts and Application of Finite Element Analysisedition, Wiley, New York, NY, USA, 3rd edition, 1989.

[22] D. L. Logan, A First Course in the Finite Element Method, Cengage Learning, 5th edition, 2012.

[23] M. Nobahari and S. M. Seyedpoor, "Structural damage detection using an efficient correlation-based index and a modified genetic algorithm," Mathematical and Computer Modelling, vol. 53, no. 9-10, pp. 1798-1809, 2011.

[24] M. R. N. Shirazi, H. Mollamahmoudi, and S. M. Seyedpoor, "Structural damage identification using an adaptive multi-stage optimization method based on a modified particle swarm algorithm," Journal of Optimization Theory and Applications, 2013. 

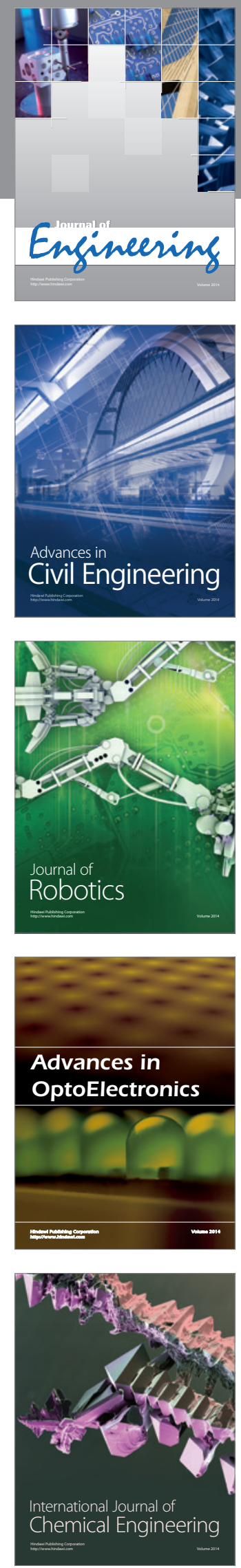

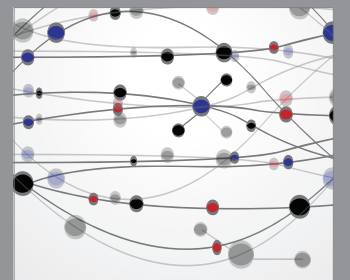

The Scientific World Journal
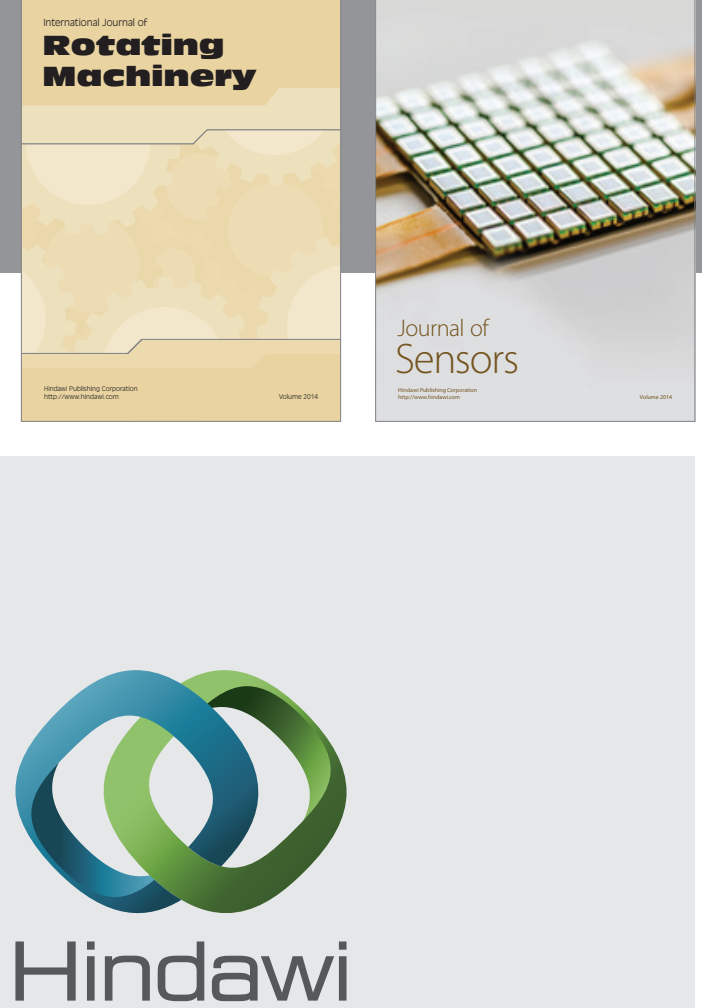

Submit your manuscripts at http://www.hindawi.com
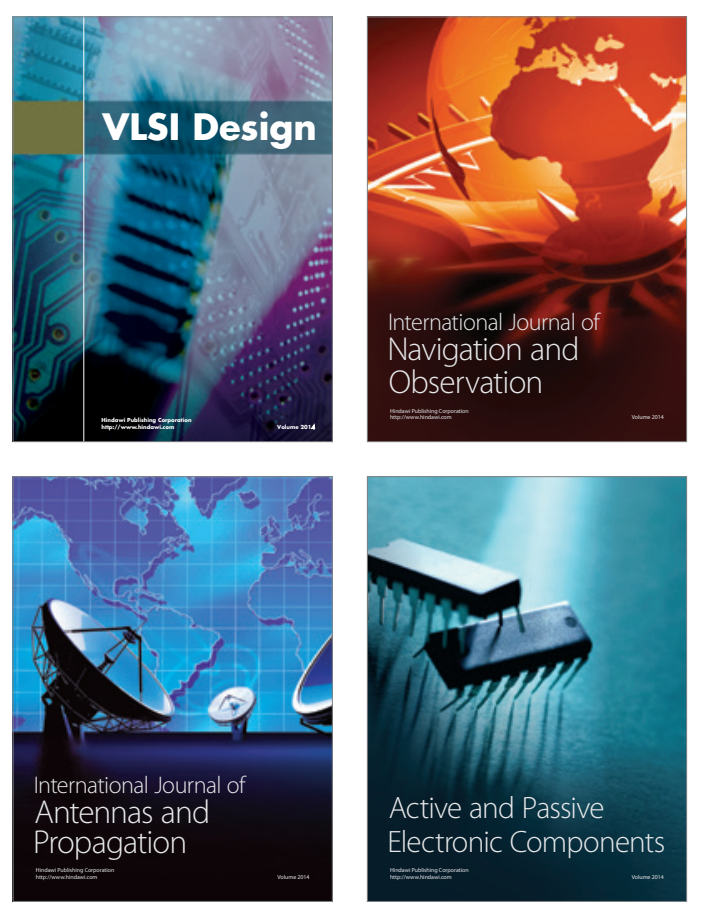
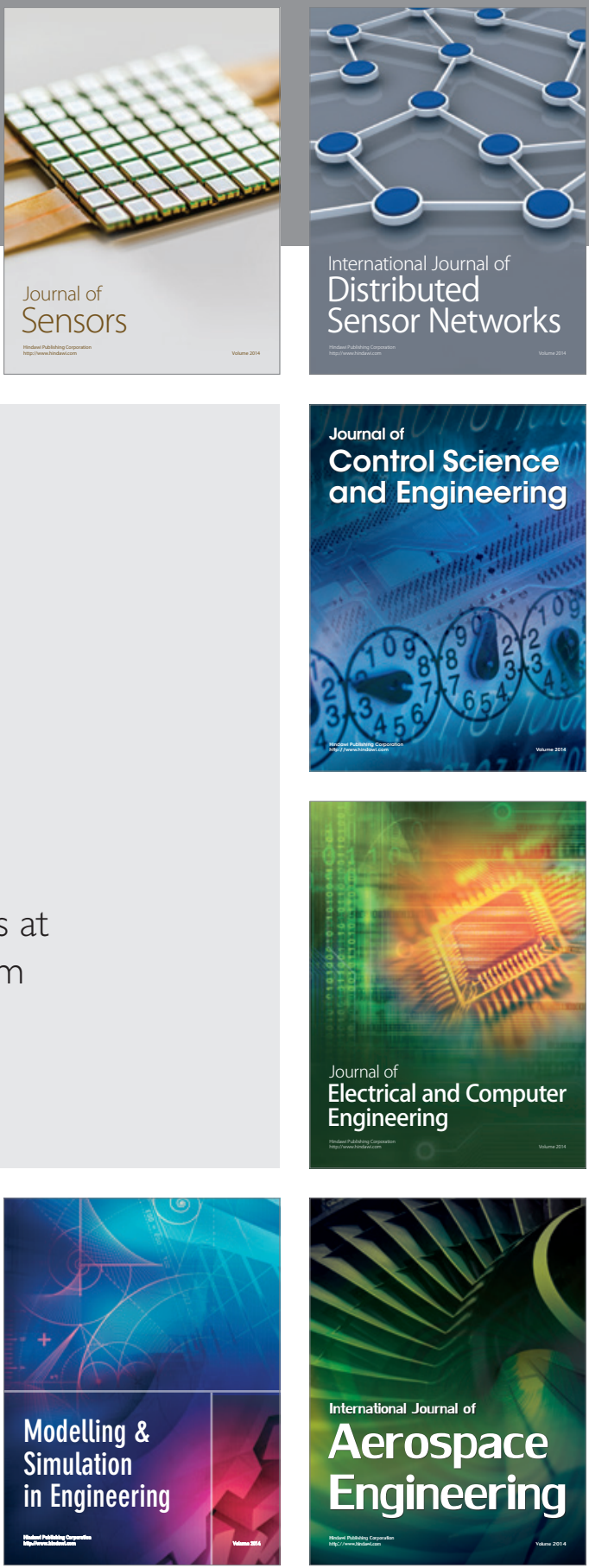

Journal of

Control Science

and Engineering
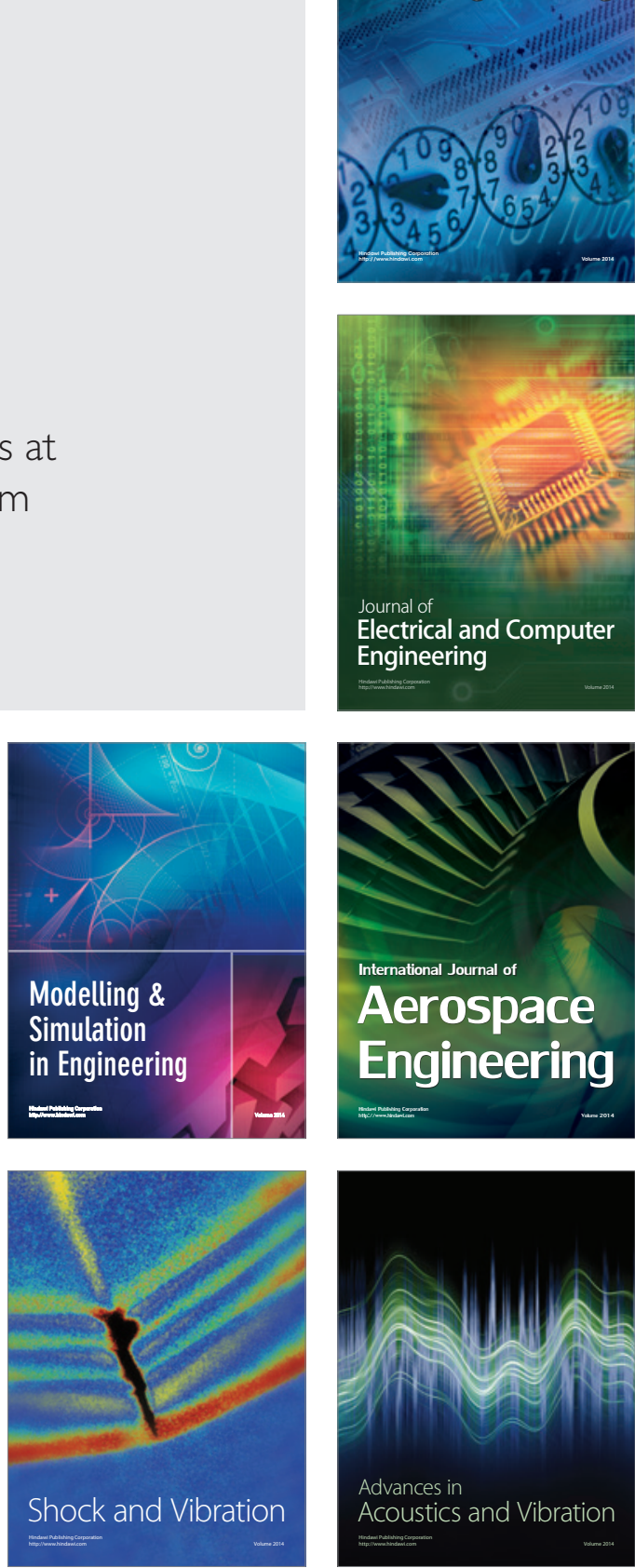